\title{
Instrumentos de Avaliação de Leitura em Fase Jnicial: habilidades e processos envolvidos
}

EARLy READING ASSESSMENT INSTRUMENTS: ABILITIES AND PROCESSES INVOLVED

Ana Cláudia de Souza* Helena Cristina Weirich**

Resumo: Este estudo investiga os seguintes instrumentos de avaliação de leitura inicial: "Bateria de Recepção e Produção da Linguagem Verbal" (SCLIAR-CABRAL, 2003a) e "Teste de Competência de Leitura de Palavras e Pseudopalavras” (SEABRA; CAPOVILLA, 2010). O principal objetivo da pesquisa é analisar, em cada um desses instrumentos de avaliação, alguns dos múltiplos processos cognitivos e habilidades básicas de leitura. Nesse sentido, são levados em conta os processos cognitivos de decodificação, reconhecimento de palavras e acesso lexical, processamento sintático e textual e compreensão. No que diz respeito às habilidades básicas de leitura, são consideradas exatidão e fluência (ritmo, prosódia e velocidade). Os resultados indicam que os instrumentos analisados avaliam diferentes aspectos da leitura em fase inicial principalmente através de medidas desconectadas (off-line). A Bateria de avaliação de Scliar-Cabral permite ao pesquisador ou ao professor avaliar os seguintes processos: percepção de oposição entre grafemas em pares mínimos e em frases, dificuldades no processamento de frases, habilidades de decodificação da relação grafêmico-fonológica e compreensão textual. A seu turno, o Teste proposto por Seabra e Capovilla permite avaliar o nível de desenvolvimento de leitura, a partir da classificação do tipo de

\footnotetext{
* Doutora em Linguística pela Universidade Federal de Santa Catarina (2004). Professora da Universidade Federal de Santa Catarina (Departamento de Metodologia de Ensino e Programa de Pós-Graduação em Linguística).Contato: ana.claudia.souza@ufsc.br. ** Mestre em Linguística pela Universidade Federal de Santa Catarina (2016). Professora do Colégio Salesiano Itajaí. Contato: helenaweirich@gmail.com.
} 
processamento do sujeito avaliado como logográfico, alfabético ou ortográfico

Palavras-chave: Avaliação de leitura. Processamento da linguagem. Habilidades básicas de leitura.

Abstract: This study investigates the following early reading assessment instruments: "Bateria de Recepção e Produção da Linguagem Verbal" (SCLIAR-CABRAL, 2003a) and "Teste de Competência de Leitura de Palavras e Pseudopalavras" (SEABRA; CAPOVILLA, 2010). The main research goal is to analyze in each one of these reading assessment instruments some of the multiple cognitive processes and basic low-level abilities involved in reading. In this sense, decoding, word recognition, lexical access, syntactic and textual processing, and comprehension are the cognitive processes taken into account. With regard to the basic reading abilities, accuracy and fluency (rhythm, prosody and speed) are considered. The results indicate that each one of the analyzed reading assessment instruments assesses different aspects of the reading processes and abilities, mainly through off-line measures. ScliarCabral's assessment battery allows the researcher or the teacher to evaluate the following processes: perception of the grapheme opposition in minimal pairs of words and in sentences, difficulties in sentence processing, skills in decoding the graphemic-phonemic relationship, and textual comprehension. In its turn, the reading assessment instrument proposed by Seabra e Capovilla allows one to evaluate student's reading development level, by classifying the kind of processing as logographic, alphabetic or orthographic.

Keywords: Reading assessment. Language processing. Basic reading skills.

\section{Introdução}

A avaliação dos processos e do desempenho em atividades que requeiram aprendizagem de objetos envolvidos na escolarização, a exemplo do sistema de escrita em suas diversas manifestações e usos, tem sido alvo de investigação em algumas áreas do conhecimento para além da educação, como a psicologia e a linguística ou a subárea de interface que se situa na intersecção entre ambas: a psicolinguística, lugar a partir do qual buscamos 
olhar para este tão importante processo envolvido na formação dos sujeitos: a aprendizagem.

Se, como sugere o título de uma das obras de Demo (2005), "Ser professor é cuidar que o aluno aprenda", cabe a nós, pesquisadores, que somos em essência e também fundamentalmente professores, investigar e estar atentos aos processos de aprendizagem e ao que eles geram em nossos estudantes.

Neste estudo, particularmente, nos dedicamos à análise e à discussão de dois instrumentos brasileiros de avaliação de leitura em fase inicial (SCLIAR-CABRAL, 2003a; SEABRA-CAPOVILLA, 2010), ou seja, de avaliação da alfabetização no que diz respeito, principalmente, ao processo de leitura, utilizados tanto em pesquisas na área da linguagem quanto nos espaços de educação básica formal e institucionalizada.

Com esta investigação, pretendemos alcançar o seguinte objetivo: analisar, nos instrumentos, suas potencialidades para avaliar questões relativas a processos cognitivos de decodificação, reconhecimento de palavras e acesso lexical, processamento sintático, compreensão básica ${ }^{1}$ e processamento textual e a habilidades básicas de leitura, tais como fluência - que envolve ritmo, prosódia e velocidade - e exatidão.

Diferentes instrumentos de avaliação de leitura têm tentado, a partir de testes de processamento e, em sua maioria, de desempenho, distinguir sujeitos alfabetizados de não alfabetizados e identificar níveis de competência, proficiência ou experiência em leitura. Como exemplos desses instrumentos, é possível citar avaliações institucionais, tais como o Programa Internacional de Avaliação de Estudantes (Pisa ${ }^{2}$ ), proposto por uma ação colaborativa dos países membros da Organização para a Cooperação e Desenvolvimento Econômico $\left(\mathrm{OECD}^{3}\right)$, cujo alvo de avaliação inclui a leitura, a Provinha

${ }^{1}$ Por compreensão básica deve-se entender, aqui, a compreensão relativa aos processos elementares de leitura, àqueles vinculados ao dito. Não se espera que, em fase inicial de aprendizagem da leitura, o leitor-aprendiz (ou o alfabetizando) tenha condições de realizar processos superiores de inferenciação, de modo a alcançar autonomamente compreensão global do texto.

2 PISA: Programme for International Student Assessment.

${ }^{3}$ OECD: Organisation for Economic Co-operation and Development. 
Brasil, que focaliza diretamente a alfabetização, a Prova Brasil e o Sistema Nacional de Avaliação da Educação Básica (Saeb), que não avaliam exclusivamente, mas incluem leitura, entre outros. O propósito anunciado desses instrumentos é, além de acessar índices educacionais, auxiliar os governos em políticas educativas e sociais.

Os instrumentos que ora analisamos nesse estudo têm propósitos gerais diferentes dos instrumentos institucionais. O que coincide é o foco, às vezes relativo, em processos e produtos de leitura. O que não coincide é o objetivo maior, uma vez que os instrumentos de Scliar-Cabral (2003a) e de Seabra e Capovilla (2010) se propõem identificar especificamente os processos e os níveis de leitura inicial de cada um dos sujeitos avaliados, a fim de poder identificar dificuldades e desvios e intervir individualmente sobre cada um deles ou sobre o conjunto de cada grupo testado, ou então, nos casos que ultrapassam os domínios educacionais, encaminhar os sujeitos a profissionais competentes da área da saúde.

\section{Método}

Os instrumentos de avaliação de Scliar-Cabral (2003a) e Seabra e Capovilla (2010) foram selecionados para análise, porque, além de responderem ao critério de avaliar leitura em fase inicial, foram elaborados para e sobre a língua portuguesa, por pesquisadores brasileiros, preocupados tanto com os resultados das pesquisas em psicologia, psicolinguística e neuropsicolinguística, como com a própria natureza do sistema alfabético e as suas implicações para o ensino e a aprendizagem. Além disso, os pesquisadores, autores dos instrumentos, têm seus nomes sedimentados em áreas que lançam olhar atento para a leitura como uma atividade individual, dependente de processos e subprocessos cognitivos, que requer aprendizagem sistematizada.

Há que se considerar, ainda, a concepção de avaliação subjacente a ambos os instrumentos, que consideram que avaliar significa diagnosticar, identificar e reconhecer o tipo de relação que o sujeito da avaliação estabelece com o objeto da aprendizagem, a partir da observação do uso deste objeto, ou seja, do sistema de escrita, na execução de tarefas, especialmente de tarefas que envolvem leitura. 
Os instrumentos analisados têm objetivos específicos diferentes e, portanto, não se espera que sejam capazes de avaliar todos os aspectos concernentes à leitura em fase inicial. Nossa proposta é a de identificar e descrever os elementos, processos e produtos selecionados e discutir as implicações dessas escolhas na avaliação de leitura em fase inicial.

A fim de alcançar os objetivos, realizamos os seguintes procedimentos metodológicos:

i) Reconhecimento e análise do referencial teórico dos instrumentos, a partir do levantamento dos conceitos de leitura e alfabetização assumidos, bem como daquilo que os autores apresentam quanto a processamento e habilidades básicas envolvidos na leitura;

ii) Descrição dos instrumentos em relação às medidas utilizadas;

iii) Verificação dos processos de leitura e habilidades básicas envolvidos nos instrumentos, por meio da análise de cada uma das tarefas;

iv) Discussão das implicações da escolha de cada um dos instrumentos na avaliação da alfabetização, a partir do exame daquilo que cada um contempla em termos de processamento e habilidades básicas.

\section{Concepções e Avaliação da Leitura em Fase Inicial}

A leitura tem sido um tema gerador de muitos estudos e foco de investigações pelo menos desde o século XIX. No entanto, apenas nas últimas décadas os processos mentais envolvidos na leitura vêm sendo, de forma mais específica, caracterizados. Esses processos são aqueles responsáveis pela transformação de algo físico, a marca escrita no papel, em unidades abstratas, que permitem a quem realiza o processamento compreender o estímulo como algo que ele não é, mas representa (LEFFA, 1996).

A avaliação da leitura em fase inicial se refere à verificação e identificação de processos que são desenvolvidos durante o período da alfabetização. Esses processos podem ser aferidos a partir de dois tipos básicos de medidas de leitura: conectadas ou desconectadas.

Em relação ao primeiro tipo, leva-se em consideração o curso temporal dos processos. De acordo com Kintsch e Rawson (2013), a medida conectada mais comum é a verificação do tempo de leitura de palavras ou de porções textuais. Outros exemplos desse tipo de medida são o tempo de resposta 
em decisões lexicais, nomeação e reconhecimento de palavras previamente apresentadas. As medidas desconectadas se baseiam na reposta dada a algum tipo de questão frequentemente posterior à atividade de leitura. Os dados obtidos a partir dos dois tipos básicos de medidas permitem inferir questões relativas ao processamento, observando-se o desempenho do sujeito avaliado.

$\mathrm{Na}$ fase inicial de aprendizagem da leitura, os processos envolvidos parecem ser, conforme explica Souza (2004), fundamentalmente ascendentes. É necessário que o aprendiz de leitura aloque seus recursos atencionais às atividades de decodificação, até que este processo básico, mas essencial, seja automatizado por meio da aprendizagem. Assim, no período de aprendizagem inicial da leitura, a compreensão do lido se caracteriza inicialmente como precária na direção de básica à medida que a aprendizagem avança, já que todo o esforço cognitivo do sujeito está focado no processo de estabelecimento de relação entre os grafemas e os fonemas correspondentes, no nível da palavra.

Posteriormente, após automatizar o processamento dos níveis elementares (o que significa ter aprendido), a leitura começa a ser aperfeiçoada e pode cumprir seu objetivo: produção de sentido e compreensão textual. Neste processo, os caminhos de desenvolvimento individuais podem ser irregulares, e diferentes tempos podem ser demandados, ainda que o objeto da aprendizagem permaneça o mesmo para todos (SEIMETZ-RODRIGUES; SOUZA, 2016).

A leitura, aqui entendida como um processo, requer incialmente a transformação do sinal visual escrito em linguagem verbal oral. Dessa maneira, implica a decodificação de um estímulo de natureza visual e é nisso que se concentram os esforços durante a fase inicial de aprendizagem da leitura. O nível de decodificação da palavra pode ser entendido como exclusivo do ato de ler (CAGLIARI, 1998; SCLIAR-CABRAL, 2003b; SOUZA, 2012). No sistema de escrita, a unidade de segmentação é a palavra. Por meio da combinação de grafemas, são constituídas palavras, as quais são separadas entre si por espaços em branco. Reconhecer esses blocos de letras é, conforme explicam Cortese e Balota (2012), a base da leitura.

$\mathrm{O}$ acesso ao texto escrito, no entanto, não diz respeito apenas ao nível da palavra, mas também ao nível da sentença. De acordo com Kintsch e Rawson (2013), esse é o nível linguístico de compreensão, que se baseia no 
reconhecimento de palavras e na sua análise em sentenças e períodos. Assim, justifica-se a ideia de que, para que seja possível caracterizar uma leitura fluente, é necessário olhar não apenas para habilidades referentes ao reconhecimento da palavra, mas também para habilidades que são evidenciadas na leitura de sentenças, tais como: prosódia, entoação, utilização de sândi externo, emprego de pausas e até mesmo velocidade de leitura, já que velocidade é um dos aspectos centrais ao processamento da informação (COWLES, 2011).

Para além do nível básico de processamento do texto e de reconhecimento da palavra, outros tipos e níveis de informação devem ser processados durante a leitura. Kintsch e Rawson (2013) categorizam essas informações como análise semântica e base textual. Outros pesquisadores também consideram os níveis superiores, elaborativos e integrativos, além dos níveis básicos, ao analisarem e descreverem o processo de leitura, a exemplo de Perfetti (1991), Bell e Perfetti (1994), Daneman (1996) e Stanovich (2000), entre muitos outros.

A aprendizagem e o uso da leitura requer, ainda, a apreensão e gradual expansão de habilidades específicas relacionadas com fluência. Nesse sentido, podemos dizer que a leitura pode ser caracterizada tanto pelos processos cognitivos envolvidos como pelo desempenho na execução da atividade de ler.

Em relação à avaliação de leitura em fase inicial, o desempenho pode ser analisado tanto a partir de respostas a questões específicas de conteúdo, em termos de correção da resposta, bem como a partir de habilidades básicas expressas na leitura em voz alta, tais como ritmo, prosódia e exatidão. Avaliar esses aspectos significa considerar e tentar identificar quais os processos que o sujeito realiza enquanto lê, ou seja, de que maneira decodifica, faz o acesso lexical, processa a sintaxe e o texto e produz sentido.

\section{Descrição e Análise dos Instrumentos}

\subsection{Bateria de recepção e produção da linguagem verbal (SCLIAR-CABRAL, 2003a)}

Em seu livro Guia prático de alfabetização, baseado em princípios do sistema alfabético do português do Brasil, Leonor Scliar-Cabral (2003a) procura orientar e fundamentar teórica e metodologicamente os alfabetizadores, detalhando 
aspectos dos processos de leitura e de escrita, do reconhecimento visual da palavra, dos processos de decodificação e da codificação gráfica.

A alfabetização é tomada como um processo de aprendizagem do sistema alfabético, a qual depende de um procedimento sistemático e planejado de ensino. Ainda, a autora faz uma diferenciação importante entre os processos de recepção e de produção na escrita, concebendo-os como interligados, mas não como dois aspectos de um mesmo processo. A recepção, para ela, precede a produção e é menos complexa, configurandose como um pré-requisito para a atividade de escrita. A escrita e a leitura são, para a autora, duas vias, com diferentes processos envolvidos. Ao defender que a recepção precede a produção, Scliar-Cabral não quer dizer que há necessariamente linearidade estrita entre os processos. O que ela defende é que aquele processo se inicia antes e é pré-requisito para este que, uma vez iniciado, pode desenvolver-se paralelamente.

Embora não explicite literalmente o que é um sujeito alfabetizado, fica claro que a alfabetização depende da compreensão, da aprendizagem e da apreensão do sistema alfabético. Ou seja, alfabetizado é quem consegue fazer relações grafêmico-fonológicas, as quais servem de base, mas não são suficientes, para o estabelecimento das relações fonológico-grafêmicas.

A leitura, alvo da alfabetização, é entendida como um processo que envolve muito mais do que apenas reconhecimento visual da palavra. $O$ objetivo final dessa atividade é sempre a compreensão, e mais, "a internalização dos conteúdos para a ampliação e aprofundamento do conhecimento" (SCLIAR-CABRAL, 2003a, p. 35). A autora diferencia os seguintes processos de leitura: motivação, pré-leitura, movimentos de fixação e sacada para fatiar a frase, reconhecimento das letras, atribuição dos valores aos grafemas e identificação do vocábulo (decodificação), atribuição do sentido às palavras, às frases e ao texto, interpretação e retenção.

Sobre esses processos, a autora, apesar de colocá-los em uma ordem cronológica, ressalta que alguns deles podem ocorrer simultaneamente. Ela parece inserir-se em uma perspectiva de compreensão baseada em esquemas, já que caracteriza o conhecimento prévio necessário para a compreensão como uma "rede estruturada de sentidos a que um assunto se refere" (SCLIAR-CABRAL, 2003a, p. 37). 
Scliar-Cabral não demonstra quais são as habilidades básicas que um sujeito alfabetizado apresenta; no entanto, propõe uma bateria de recepção e produção da linguagem que vincula habilidades básicas expressas no desempenho e no processamento, com base nos princípios alfabéticos do português brasileiro, tendo o cuidado de controlar processamentos outros que podem influenciar na alfabetização, a exemplo da capacidade de percepção de oposição de fonemas na oralidade e do desenvolvimento de esquemas narrativos. O grande objetivo da bateria é "detectar sintomas mais evidentes sobre desvios da recepção oral e escrita e respectiva produção" (SCLIAR-CABRAL, 2003a, p. 119).

O aplicador da bateria é aconselhado a não fazer um diagnóstico a partir dos testes, mas apenas verificar sintomas e encaminhar o sujeito para profissionais competentes. É importante ressaltar que o instrumento não passou por validação ou normatização, o que significa que não há, ainda, parâmetros comparativos para a análise dos resultados obtidos.

A bateria é composta por nove etapas, constituídas por blocos de testes ou testes individuais. As três primeiras etapas dizem respeito à percepção e produção oral e ao desenvolvimento de esquemas narrativos. As demais avaliam questões relativas à leitura e à escrita. A bateria está descrita com base nas instruções contidas nas páginas 119 a 250 do Guia Prático de Alfabetização (SCLIAR-CABRAL, 2003a).

Os dois primeiros testes (1.1 - Recepção auditiva; 1.2 - Compreensão de frases) objetivam detectar se o indivíduo possui problemas na distinção de traços fonéticos e se compreende frases de complexidade crescente. No primeiro teste (1.1), o aplicador apresenta uma cartela com imagens e pede que o indivíduo indique a imagem correspondente à palavra falada pelo aplicador, que deve estar posicionado atrás do sujeito testado.

Como exemplo dessa atividade, mostramos a primeira cartela (Imagem 1), na qual estão distribuídas aleatoriamente seis imagens: pote e bote, gato e gado, vaca e faca. O aplicador falará as palavras "gado", "bote" e "vaca". A cada palavra falada pelo aplicador, o sujeito deve apontar a imagem correspondente. 


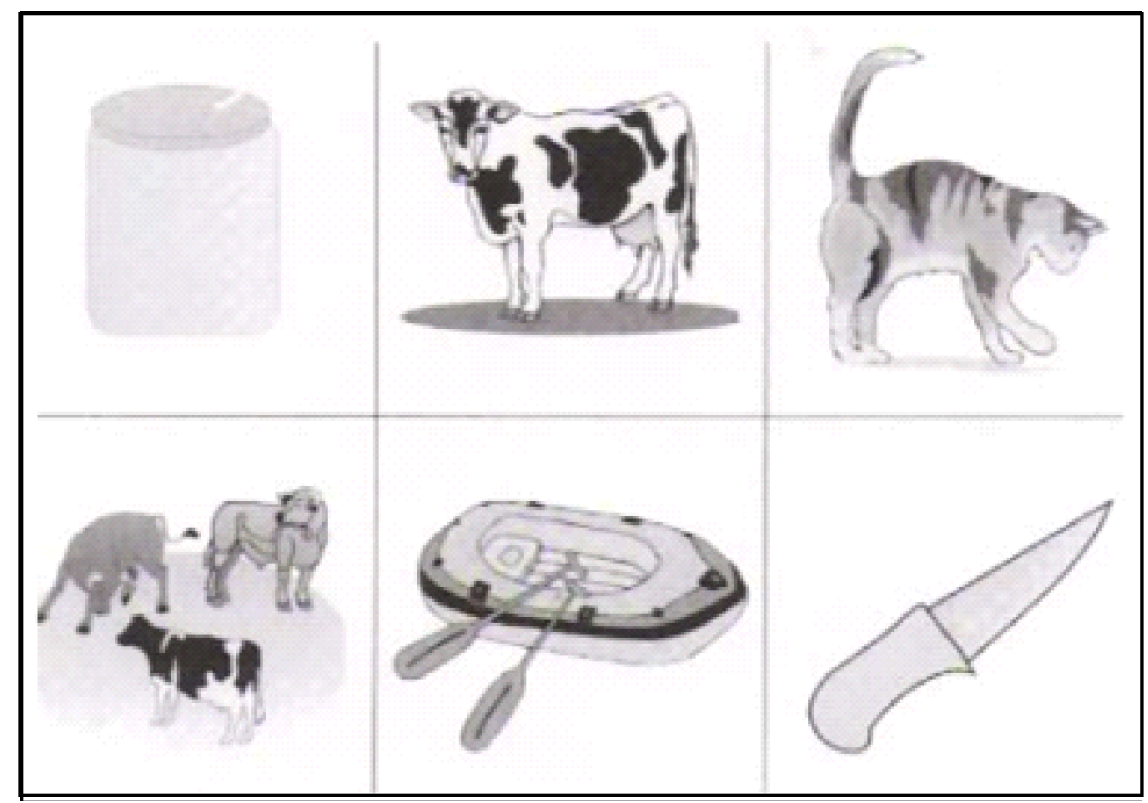

Fonte: Scliar-Cabral (2003a, p. 145).

Figura 1: Exemplo de cartela utilizada no teste de recepção auditiva (1.1)

De acordo com o tipo de erro e sua repetição, a análise dos resultados poderá ser de que o examinando apresenta ou não problemas relativos à percepção do traço sonoro. Outras oposições sonoras são verificáveis nas demais cartelas.

No segundo teste (1.2), as palavras são substituídas por frases, que visam testar: percepção auditiva de frases, compreensão das relações espaciais, memória de trabalho, competência para processar a voz passiva e capacidade de processamento.

Para melhor compreensão, vejamos exemplos das frases utilizadas neste teste: (1) a menina come; (2) o gato está em cima da mesa; (3) o porco toma água e o frango pega as maçãs; (4) a menina foi derrubada pelo menino; (5) o sapato que a menina está amarrando é branco.

Quando ao sujeito, é apresentada a frase (2) “o gato está em cima da mesa”, e ele deve optar entre uma das imagens que seguem: 


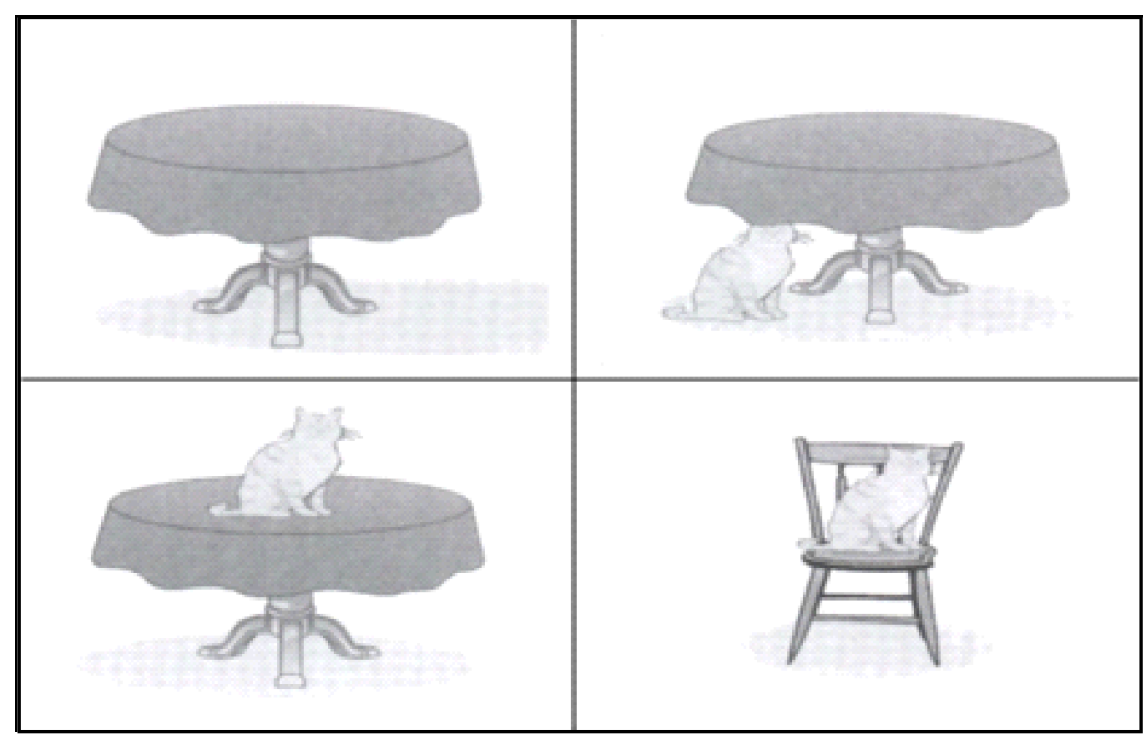

Fonte: Scliar-Cabral (2003a, p. 175).

Figura 2: Cartela utilizada no teste de compreensão de frases (1.2)

Podemos observar, com isso, que as imagens não relacionadas com a frase falada contêm elementos que podem, propositalmente, levar o sujeito a escolher a opção errada, o que revelaria sintomas de problemas na compreensão, neste caso específico, no que diz respeito às relações espaciais.

O segundo bloco de testes (2.1 - Produção oral de palavras; 2.2 - Produção oral de frases) pretende verificar se o sujeito domina os gestos fonoarticulatórios e se produz frases adequadas às imagens. No primeiro momento (2.1), o aplicador aponta para as mesmas imagens utilizadas no teste de compreensão de palavras e solicita a produção do aluno. No segundo momento (2.2), o mesmo procedimento é adotado, agora com as frases, e as seguintes questões podem ser avaliadas: unidades coesivas que diferenciam masculino e feminino e traços semânticos dos verbos; planejamento de relações espaciais; planejamento de cadeias longas; produção da vOz passiva; capacidade de planejamento e execução, se o foco continua ativado na memória de trabalho quando vem substituído na oração adjetiva pelo pronome relativo. 
O terceiro teste (3 - Invenção a partir de uma sequência de gravuras) objetiva aferir o desenvolvimento de esquemas narrativos. Para tanto, o examinando deve ordenar imagens em uma sequência temporal, constituindo uma narrativa. O sujeito observa 5 cartelas em ordem aleatória contendo as seguintes situações: (1) Menino e cachorro diante de farol com sinal vermelho iluminado; (2) O cachorro se desprende e tenta atravessar a rua; (3) O cachorro é atropelado por um carro; (4) $\mathrm{O}$ menino sai da ambulância, carregando o cachorro ensanguentado diante do hospital; (5) O menino traz um buquê de flores para o cachorro com a perna na tipoia no leito do hospital. O sujeito deve reorganizar as cartelas e, em seguida, contar a história inventada.

O quarto teste (4 - Reconto da história "O galo vaidoso") também se relaciona com a verificação do desenvolvimento de esquemas narrativos, juntamente com a testagem de habilidades de ordenação. $\mathrm{O}$ aplicador lê uma história, intitulada "O galo vaidoso" e o sujeito deve recontá-la oralmente. História a ser recontada (SCLIAR-CABRAL, 2003a, p. 131-132):

1. Era uma vezum galo vaidoso

2. que vivia cantando sozinho no poleiro.

3. Um macaco e um cachorro moravam perto

4. e sempre saíam pra colher banana

5. e nadar no rio.

6. Um dia, cain um raio no galinheiro

7. e começou a pegar fogo.

8. Então o galo gritou:

9. - Socorro!

10. Só havia um jeito de apagar o fogo:

11. era fazer uma fila dos bichos desde o rio até o galinheiro

12. e passar um balde com água de mão em mão

13. e despejá-lo sobre as chamas.

14. Foi o que a turma fez:

15. Então o galo desceu do poleiro.

16. Tossindo no meio da fumaça, agradeceu:

17. - Se não fosse vocês,

18. eu tinha virado galeto.

19. Acabou. 
O quinto bloco de testes (5.1 - Emparelhamento de palavras; 5.2 Emparelhamento de frases) tem como foco verificar as habilidades de percepção de oposição entre grafemas em pares mínimos e em frases. No teste 5.1, o sujeito deve colocar fichas com palavras escritas ao lado das imagens correspondentes, com as mesmas palavras e imagens que foram utilizadas no teste 1.1. No entanto, agora, as palavras são utilizadas na forma escrita.

O mesmo procedimento é realizado no teste seguinte (5.2), agora a partir do emparelhamento de frases com imagens. Novamente, as frases e imagens utilizadas são as mesmas do teste 1.2. Por exemplo, o sujeito recebe a uma ficha com frase "O cachorro foi derrubado pela menina" e deve colocá-la sobre a imagem correspondente na cartela que segue:

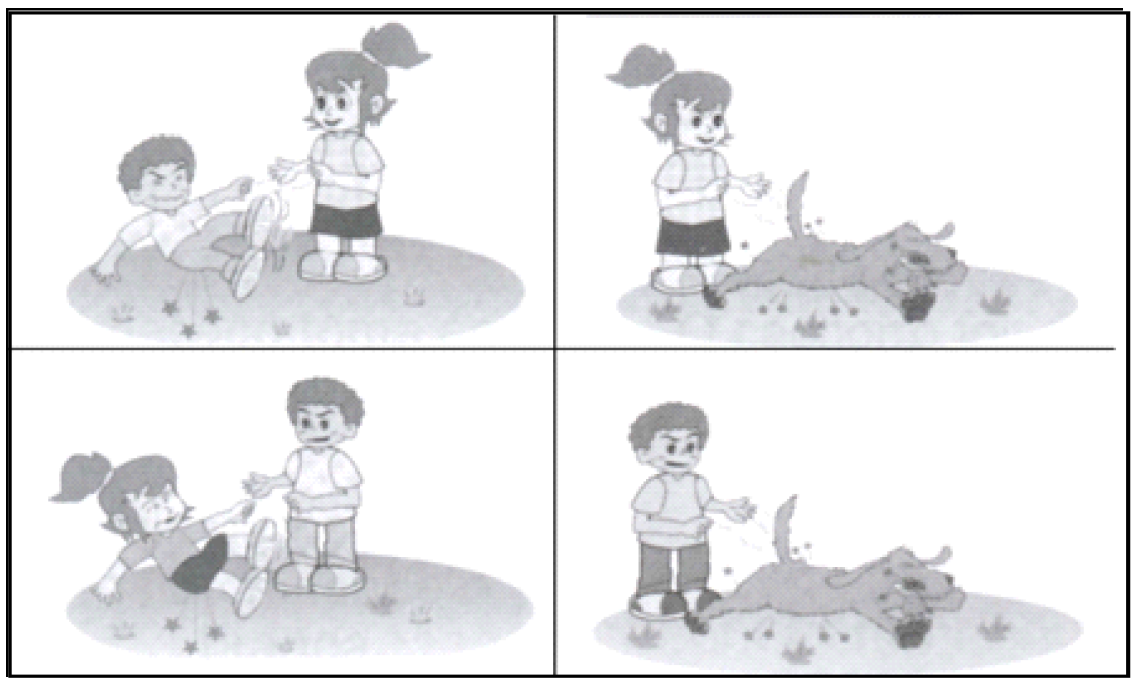

Fonte: Scliar-Cabral (2003a, p. 177).

Figura 3: Cartela utilizada no teste de emparelhamento de frases (5.2)

O sexto bloco (6.1 - Produção escrita de palavras; 6.2 - Produção escrita de frases) objetiva verificar a transposição das representações fonológicas em texto escrito. Nos testes, o sujeito deve escrever palavras e, em seguida, frases, ao lado das imagens correspondentes. Diferentemente do que se avalia no 
bloco 5 (emparelhamento de imagens com palavras e frases), aqui somente a imagem é vista pelo sujeito. Ele é quem deve produzir a palavra e a frase com base na imagem vista. Este é o único bloco de testes que pode ser aplicado coletivamente.

O sétimo teste ( 7 - Teste de correspondência fonológico-grafêmica) objetiva verificar se o sujeito testado conhece as regras de codificação. O teste utiliza pseudopalavras, as quais são ditas pelo aplicador e devem ser identificadas pelo sujeito, que terá uma série de opções escritas em fichas de papel. Por exemplo, ao ouvir a pseudopalavra "pudo", o examinando deve indicar um dos itens da tira a seguir:

\section{\begin{tabular}{|l|l|l|l|l|l|}
\hline & pudo & budo & qudo & lopa & pude \\
\hline
\end{tabular}}

Fonte: Scliar-Cabral (2003a, p. 195).

Figura 4: Tira utilizada no teste de correspondência fonológico-grafêmica (7)

Neste teste, o aplicador pode observar as seguintes dificuldades: percepção da distinção do traço fonético num par mínimo e sua respectiva codificação grafêmica; percepção dos traços gráficos; adivinhação ou alfabetização pelo nome das letras; falta de domínio das regras de codificação determinadas pelo contexto fonético/fonológico.

No oitavo teste ( 8 - Teste de correspondência grafêmico-fonológica), todas as palavras utilizadas são pseudopalavras. Basicamente, o aplicador aponta para uma pseudopalavra que deve ser lida, a exemplo do que consta da Figura 4. Nesse caso, podem ser identificados os seguintes problemas de leitura: dificuldade de articular o traço que diferencia pares mínimos; dificuldade de perceber distinções ocasionadas pelo traço de rotação ou combinatória de outros traços; adivinhação ou leitura pelo nome da letra; falta de domínio da regra de correspondência grafêmico-fonológica; problemas fonoarticulatórios. O aplicador deve anotar a produção da criança e, a partir da análise dos erros, identificar os possíveis problemas. 
O último bloco se refere a testes de leitura de textos, que avaliam decodificação e compreensão (9.1 - Teste de leitura em vozalta; 9.2 - Compreensão de leitura). O primeiro deles (9.1) permite confirmar a capacidade de decodificação e perceber outros problemas de leitura, pois, enquanto o indivíduo lê o texto, o aplicador deve observar quantas ocorrências acontecem dos seguintes aspectos: prolongamento de vogais e consoantes contínuas, pausas silenciosas, pausas plenas, rupturas de sândi externo, palavras incompletas, repetição de sílabas, distorções, adivinhações, repetições de palavras ou frases, marcas de pontuação desrespeitadas, leitura monocórdia e leitura expressiva. Texto a ser lido pelo examinando (SCLIAR-CABRAL, 2003a, p. 211):

\section{O TATU ENCABULADO}

Era uma vez. um tatu que morava numa toca. Ele era muito encabulado e ficava escondido na toca. O sapo e o macaco resolveram convidar o tatu. Tatu, por que você não vem brincar com a gente? Nós vamos brincar de bolinha de gude. Você quer? Ab! Mas os meus dedos são muito pequenos - disse o tatu. Não faz. mal! Você também pode jogar com o rabo. E lá foram os três jogar bolinha de gude. Assim o tatu saiu da toca e ficaram amigos.

O segundo teste de leitura de textos (9.2) avalia a compreensão. O sujeito deve marcar com um " $\mathrm{x}$ " frases que estão de acordo com o texto lido silenciosamente, que é o mesmo do teste anterior, "O tatu encabulado". O teste de compreensão é composto pelos itens seguintes (SCLIARCABRAL, 2003a, p. 212):

1. ( ) O tatu era muito exibido.

2. ( ) O tatu era muito envergonhado.

3. () O tatu morava numa casa com muita gente.

4. ( ) O tatu morava sozinho num barco.

5. ( ) O macaco e o sapo quiseram brincar com o tatu.

6. ( ) Só o sapo quis brincar com o tatu.

7. ( ) O jogo escolhido foi com bolinha de gude.

8. ( ) O macaco e o sapo não sabiam jogar com bolinha de gude. 
9. ( ) O tatu disse que podia jogar com os dedos.

10. ( ) O tatu achava que seus dedos eram muito pequenos.

11. ( ) O sapo, o macaco e o tatu ficaram amigos.

Os testes descritos são de diferentes naturezas. Basicamente, no que diz respeito a desempenho em leitura, avaliam habilidades relacionadas a conhecimentos linguísticos e a produto da decodificação e compreensão básica, quais sejam: percepção dos traços gráficos, reconhecimento de grafemas, realização do sândi externo, uso de pausas, prosódia, entoação, exatidão, compreensão frasal e microestrutural e linear em relação à organização do texto. Ainda, segundo a autora, permitem verificar dificuldades específicas do processamento de frases, compreensão e memória.

Vale ressaltar que a bateria de testes depende de um exame cuidadoso do aplicador, pois a análise dos resultados não depende de uma correlação entre número de erros e dificuldade de leitura. $\mathrm{O}$ aplicador precisa observar aspectos relacionados a sutilezas, o que depende de conhecimento prévio e sedimentado dos itens analisados.

Em relação ao processamento da leitura, o instrumento permite verificar: habilidades de percepção de oposição entre grafemas em pares mínimos e em frases; dificuldades no processamento de frases; habilidades de decodificação grafêmico-fonológica, podendo indicar se o sujeito faz uso da rota fonológica para a leitura.

Além disso, o instrumento permite correlacionar os resultados nos testes de leitura e escrita com os testes de recepção e produção oral, o que possibilita verificar se o sujeito apresenta dificuldades no processamento da linguagem de forma geral, ou apenas no sistema de escrita. Salvo o teste de leitura em voz alta (9.1), as demais medidas realizadas são desconectadas, ou seja, olham para o resultado da leitura realizada, não para o processo de realização.

Ao verificar a rota de acesso ao léxico, o único efeito manipulado nos estímulos é o lexical (são usadas palavras ou pseudopalavras nos testes), o que torna o instrumento limitado para avaliar o reconhecimento visual de palavras, pois não considera aspectos frequência e extensão das palavras. Além disso, a atividade de emparelhamento de frases com figuras pode indicar dificuldades no processamento de frases. No entanto, não há uma 
determinação sobre quais dificuldades seriam estas, se sintáticas ou relacionadas à compreensão. Nesse sentido, o instrumento, como esclarecido pela própria autora (SCLIAR-CABRAL, 2003a), indica sintomas de desvios em recepção e produção. Especificamente sobre leitura, é capaz de prever problemas em diferentes níveis, mas não permite a distinção clara e inequívoca entre um sujeito alfabetizado e não alfabetizado.

3.2 Teste de competência de leitura de palavras e pseudopalavras - TCLPP (SEABRA, CAPOVILLA, 2010)

O "Teste de competência de leitura de palavras e pseudopalavras TCLPP” (2010) foi elaborado pelos pesquisadores brasileiros Alessandra Gotuzo Seabra e Fernando César Capovilla, atuantes na área de psicologia experimental, com interesse em temas relativos à leitura como atividade cognitiva, dependente de outros processos cognitivos.

A elaboração do instrumento foi pautada pela ideia de que o desenvolvimento durante a alfabetização pode ser caracterizado por três estágios, nos quais diferentes rotas ou estratégias de leitura são empregadas: logográfico, alfabético e ortográfico.

Ainda que não explicitem textualmente o conceito de alfabetização ou de leitura subjacente ao instrumento, ao assumirem os três estágios, identificados nos modelos de desenvolvimento de Frith e Morton ${ }^{4}$, revelam como a leitura inicial é concebida. O primeiro dos estágios é o logográfico, no qual o signo escrito é processado da mesma maneira que um desenho, compreendido globalmente. Em um segundo estágio, o alfabético, a criança compreende a relação entre oralidade e escrita. Nesse momento, grafema e

${ }^{4}$ Seabra e Capovilla citam, como base de sua concepção de aprendizagem da leitura em estágios, as seguintes publicações de Frith e Morton: 1) FRITH, U. Beneath the surface of developmental dyslexia. In: PATTERSON, K.; MARSHALL, J.; COLTHEART, M. (Eds.). Surface dyslexia: neuropsicological and cognitive studies of phonological reading. London, UK: Erlbaum, 1985. 2) FRITH, U. Dyslexia as a developmental disorder of language. London, UK: MRC, Cognitive development unit, 1990.3) MORTON. J. An information-processing account of reading acquisition. In: GALABURDA, A. M. (Ed.). From reading to neurons. Cambridge, MA: MIT Press. 1989. p. 43-68. 
fonema passam a ser decodificados e codificados, a partir do entendimento do sistema de representação. No terceiro estágio, o ortográfico, a criança é capaz de ler de forma visual direta as palavras mais frequentes na leitura.

Esses estágios estão relacionados com os processos envolvidos no reconhecimento das palavras. São descritas três rotas alternativas: logográfica, relacionada ao primeiro estágio; fonológica, utilizada no segundo estágio; e lexical, relacionada com o terceiro estágio de desenvolvimento. As rotas são utilizadas para que se acesse o léxico mental, o que permite a compreensão do que é lido, no nível da palavra.

Os autores ressaltam que o instrumento possui caráter psicométrico. Nesse sentido, objetiva avaliar o desempenho da criança em relação aos seus pares, a partir da análise das tabelas de normatização disponíveis no manual.

Além disso, o TCLPP caracteriza-se como um instrumento neuropsicológico cognitivo, já que permite observar o estágio de desenvolvimento de leitura do sujeito e inferir o tipo de processamento utilizado. Dessa forma, podem ser elencadas as dificuldades específicas de cada sujeito avaliado, bem como de seu grupo.

Para tanto, são utilizados itens linguísticos, que podem ser palavras ou pseudopalavras, pareados com imagens. Esses pares se caracterizam pela adequação ou não entre palavra e imagem e pela forma como a palavra é escrita.

O teste, que tem sua versão em papel e também computadorizada, é composto por 78 itens, sendo 70 de teste e 8 de treino. Basicamente, o teste contém pares de imagem e palavra escrita de sete tipos, as quais devem ser lidas silenciosamente pelo examinando (exemplos no Quadro 1). O sujeito avaliado tem como tarefa cruzar os pares incorretos e circular os pares corretos. Ao corrigir o teste, deve-se considerar como acerto o círculo sobre os itens 1 e 2 e o "X" sobre os itens restantes. Ou seja, a aceitação dos dois primeiros tipos de itens (correta regular e correta irregular) e a rejeição dos demais são consideradas acertos.

A análise do tipo de erro é o que permite verificar qual a natureza da dificuldade de leitura de uma criança. Os autores propõem padrões baseados na distribuição de erros, que indicam graus de dificuldade de processamento. As validações do teste permitiram verificar que o tipo de erro cometido pela criança está relacionado com a estratégia esperada para a leitura e a estratégia aplicada pelo sujeito. 
Quadro 1: Exemplos de pares de imagem e palavra - TCLPP

\begin{tabular}{|c|c|c|}
\hline Tipo & Relação entre palavra e imagem & $\begin{array}{c}\text { Pares de imagem e palavra ou } \\
\text { pseudopalavra }\end{array}$ \\
\hline 1 & Correta regular (CR) & $F A D A$ \\
\hline 2 & Correta irregular (CI) & $T A X I$ \\
\hline 3 & Vizinhas semânticas (VS) & $\mathrm{R} A \dot{D} I O$ \\
\hline 4 & Vizinhas visuais (VV) & TEIEUIS $\tilde{A O}$ \\
\hline 5 & Vizinhas fonológicas (VF) & MÁCHICO \\
\hline 6 & Pseudopalavras homófonas (PH) & JÊEIU \\
\hline 7 & Pseudopalavras estranhas (PE) & MELOCE \\
\hline
\end{tabular}

Fonte: Seabra; Capovilla (2010, p. 9). 
Segundo os autores, os itens do tipo 1, 3 e 7 (correta regular, vizinhas semânticas, pseudopalavras estranhas) podem ser lidos a partir da aplicação de qualquer uma das estratégias, o que resulta em uma facilidade maior de leitura. Para que os itens do tipo 4 e 5 (vizinhas visuais e fonológicas) sejam rejeitados pelos sujeitos, constituindo um acerto no teste, esses não podem ser lidos pela estratégia logográfica, somente pelas estratégias fonológica e lexical. Já as palavras do tipo 2 (corretas irregulares) devem ser lidas pela estratégia logográfica ou lexical, já que a estratégia fonológica não permitiria o acesso ao léxico. As palavras do tipo 6 (pseudopalavras homófonas) somente podem ser lidas corretamente através da estratégia lexical, em vista de que possuem a forma visual semelhante e fonológica idêntica à palavra correta.

Se a criança rejeita palavras corretas grafofonemicamente irregulares, como "Táxi", ela demonstra dificuldades de processamento lexical ou sua ausência. A mesma dificuldade está relacionada com a aceitação de pseudopalavras homófonas, como "Jêniu”. Nesse caso, a decodificação estaria sendo realizada apenas pela rota fonológica. A aceitação de pseudopalavras com trocas fonológicas, como "Máchico", indica falta de recurso ao léxico e dificuldades no processamento fonológico. A aceitação de palavras semanticamente incorretas, como do tipo 3, indica falta de acesso ao léxico semântico. A aceitação de pseudopalavras com trocas visuais, como "Teieuisão", pode demostrar dificuldade no processamento fonológico e recurso à estratégia logográfica. Por fim, a aceitação de palavras estranhas, como em 7 , pode indicar ausência de processamento lexical, fonológico e logográfico.

Os autores apresentam estudos prévios com o TCLPP, os quais têm mostrado que o instrumento tem validade para "mapear o processamento cognitivo de leitura em crianças” (SEABRA; CAPOVILLA, 2010, p. 13). São citados dezenas de estudos organizados por Seabra e Capovilla e outros autores, os quais apresentam evidencias empíricas de que o instrumento é válido para verificar estágios do desenvolvimento em leitura e inferir os processos mentais envolvidos nessa atividade. Ainda, os autores detalham um estudo global para análise de precisão, validade e normatização do instrumento, o qual foi realizado com 2.988 estudantes de escolas públicas e privadas do estado de São Paulo. Este estudo permitiu verificar que as médias 
alcançadas pelos sujeitos diferem significativamente umas das outras no decorrer da primeira etapa do ensino básico, desde a primeira até a quarta série. Em cada uma dessas séries os alunos desenvolvem as rotas de acesso ao léxico avaliadas. Esse estudo permitiu a geração de tabelas de normatização que permitem, ao aplicador do instrumento, verificar se o sujeito avaliado está dentro da média da série a qual pertence, tanto em relação ao escore geral como em relação à média em cada um dos itens linguísticos.

Esse instrumento foca no reconhecimento visual da palavra, oportunizando a verificação do estágio de desenvolvimento de leitura, a partir da classificação do processamento do sujeito avaliado como logográfico, alfabético - equivalente à rota fonológica -, ou ortográfico - equivalente à rota lexical. $\mathrm{O}$ instrumento oportuniza, ainda, a comparação do sujeito com seus pares.

O instrumento se caracteriza pela ideia de que o reconhecimento de palavras é dependente do uso de rotas de acesso ao léxico. Em relação a isso, importantes contribuições foram propostas pelo modelo de duplarota de leitura (ver COLTHEART, 2013), o qual sugere a existência de dois caminhos no reconhecimento de palavras: a rota lexical e a não lexical (fonológica). Essas rotas são verificadas a partir da manipulação de itens lexicais, o que permite a verificação de efeitos como frequência, regularidade, extensão e lexicalidade no processamento da leitura. De acordo com a exatidão com que o sujeito lê uma palavra manipulada, infere-se o tipo de processamento que está sendo executado.

A avaliação do uso dessas rotas é fundamental para a distinção entre sujeitos alfabetizados e não alfabetizados, já que os estudos sobre o reconhecimento visual da palavra, realizados com aprendizes de leitura do português brasileiro, têm demonstrado, experimentalmente, que, em fase inicial de aprendizagem, os sujeitos utilizam, prioritariamente, a rota fonológica, a qual, gradualmente, vai dando espaço à rota lexical (LÚCIO; PINHEIRO, 2009). Morais, Kolinsky e Grimm-Cabral (2004) demonstram que uma criança que utiliza a rota fonológica precisa de 3 segundos para ler uma palavra dissílaba. Já uma criança que utiliza o acesso direto ao léxico precisa apenas de 140 milésimos de segundo para ler a mesma palavra. Isso demonstra que o acesso lexical otimiza o processamento, o que permite uma leitura minimante rápida, necessária para os processos de compreensão. 
O instrumento não leva em consideração a leitura em voz alta, o que se configura como uma limitação de acesso ao processamento. Apenas em sua versão computadorizada é possível mensurar o tempo de resposta. Além disso, atua no nível da palavra, o que não permite avaliar aspectos de processamento que vão além do reconhecimento da palavra, como o processamento sintático ou diferentes níveis de compreensão. Assim, ainda que a rota de acesso ao léxico empregada seja um bom indicativo de alfabetização, a utilização desse único critério não permite a distinção entre sujeito alfabetizados e não alfabetizados.

Há que se considerar também algumas possíveis inconsistências na terminologia empregada para caracterização dos itens, ainda que tal problema possa não interferir nos resultados, salvo no que diz respeito à consistência teórica. No exemplo de vizinhas semânticas apresentado no Quadro 1, do qual consta uma imagem de telefone a ser relacionada à palavra rádio, somente se pode imaginar vizinhança semântica se se pensar em rádio como aparelho de comunicação, de interação a distância entre os sujeitos. Caso se acesse o sentido de rádio como estação ou emissora que difunde programas de radiofusão, a vizinhança semântica parece perder seu efeito. No que diz respeito às vizinhas visuais e fonológicas, observa-se, nos exemplos do Quadro 1 , que os elementos que são solicitados a serem relacionados às imagens constituem pseudopalavras ("teieuisão" e "máchico") e, por isso, há que se ter cautela em falar de vizinhança, já que esta pressupõe a existência da palavra. Verdade é que se trata de pseudopalavras bastante próximas às palavras, mas, ainda assim, não se pode conferir o caráter de palavras existentes na língua a elas, a menos que se considere o léxico na fase de aquisição fonológica, o que não parece ser o caso do instrumento psicométrico aqui analisado. Quanto às pseudopalavras homófonas, os exemplos selecionados para os testes não são pseudopalavras efetivamente. "Gênio" grafado com “j” e "u", como em "jêniu", evidencia erro ou equívoco de grafia em contexto competitivo, não pseudopalavra, já que continua sendo a palavra /’je.niu/.

\section{Discussão e Considerações Finais}

A literatura referente ao processamento da leitura situa o reconhecimento visual da palavra como o processo sobre o qual deve atuar 
a alfabetização. Ainda, como visto, pode-se conceber o processamento das sentenças como outro aspecto a ser manipulado e automatizado durante a aprendizagem inicial de leitura. Além disso, juntamente com a compreensão, habilidades básicas expressas durante a leitura em voz alta devem ser levadas em consideração para que a leitura competente seja caracterizada como tal. Entre elas estão ritmo, prosódia, velocidade e a precisão de leitura.

Os instrumentos analisados neste artigo permitem observar que avaliar alfabetização é, de fato, uma tarefa complexa. Com isso, é necessário que sejam feitas escolhas que, logicamente, levam a resultados e avaliações diferentes. O TCLPP dá indícios de problemas no processamento e no nível de desenvolvimento da leitura, somente no que diz respeito ao reconhecimento da palavra escrita. Também, permite a comparação do sujeito com seus pares. Já a Bateria é um instrumento mais abrangente, que indica sintomas de desvios em recepção e produção oral e escrita. Especificamente sobre leitura, é capaz de prever problemas em diferentes níveis, tanto no que diz respeito às habilidades de execução (realização do sândi externo, uso de pausas, prosódia e precisão), bem como no que se refere ao processamento e ao desempenho (decodificação grafêmico-fonológica, dificuldades no processamento de frases, e aspectos da compreensão frasal e textual). No entanto, depende de uma análise cuidadosa do aplicador/pesquisador que deve inferir esses "desvios" a partir do comportamento do sujeito em cada teste. A Bateria leva em consideração as habilidades de execução de leitura e as toma como referência para caracterizar e avaliar um leitor.

É importante considerar que os dois instrumentos pouco contemplam medidas conectadas, salvo no que diz respeito a um dos testes da Bateria e à possibilidade de mensuração do tempo de resposta na versão computadorizada do TCLPP. Em função disso, perde-se um detalhamento sobre a velocidade dos processos subjacentes ao desempenho observado, o que poderia fornecer informações sobre o nível de leitura dos sujeitos, sobre suas dificuldade e sobre eventuais desvios de aprendizagem.

A partir disso, concluímos que os instrumentos apresentados atuam em diferentes aspectos da leitura inicial, o que era esperado, uma vez que cada uma das propostas toca e mensura aspectos diversos, em extensões também diversas, das habilidades e processos de leitura inicial. Para que seja possível avaliar alfabetização da forma mais global e eficiente possível, é 
necessária uma acoplagem entre os instrumentos, coordenando medidas de processamento e verificação de habilidades básicas de leitura. Uma avaliação de alfabetização deve contemplar: padrões de processamento - qual a rota de acesso ao léxico utilizada, processamento sintático e nível de compreensão - e medidas relacionadas às habilidades básicas (fluência - ritmo, prosódia, velocidade - e precisão). Ainda, faz-se necessário medir essas questões de forma numérica, sendo possível comparar o sujeito com os seus pares.

Conforme apontam Nation e Snowling (1997), a avaliação precisa de dificuldades de leitura é claramente importante se oferecer suporte e alternativas de remediação apropriadas para minimizar as dificuldades ou os desvios. Nesse sentido, há que se considerar que, quanto aos processos e às atividades avaliativas, para que se possa atuar com os sujeitos em suas ações leitoras, precisamos conhecer quem estes sujeitos são como leitores. Partir do pressuposto de que sabem ou não sabem ler, com base apenas na experiência com a escolarização, não oferece pistas consistentes e confiáveis acerca dos supostos ou desejados leitores. Por isso, é fundamental que se avaliem, reconheçam e assumam as dificuldades e os conhecimentos já sedimentados, a fim de que se possa interagir e intervir devidamente nos espaços escolares e clínicos, de modo a, efetivamente, criar condições para a existência e o desenvolvimento de sujeitos leitores autônomos. Como, poeticamente, nos alertou Monteiro Lobato, "Quem mal lê, mal ouve, mal fala, mal vê". Portanto, nos permitamos ver, ouvir e falar e aceitemos que avaliar é parte do cotidiano de nossas vidas e é fundamental quando o assunto diz respeito a processos de aprendizagem.

\section{Referências}

BELL, L. C.; PERFETTI, C. A. Reading skills: Some adult comparisons. Journal of Educational Psychology, v. 86, p. 244-255, 1994.

CAGLIARI, L. C. Alfabetizando sem o bá-bé-bi-bó-bu. São Paulo: Scipione, 1998.

COLTHEART, M. Modelando a leitura: a abordagem da dupla rota. In: SNOWLING, M. J.; HULME, C. (Org.). A ciência da leitura. Porto Alegre: Penso, 2013. p. 24-41. 
CORTESE, M. J.; BALOTA, D. A. Visual word recognition in skilled adult reader. In: SPIVEY, M. J.; MCRAE, K.; JOANISSE, M. F. (Ed.). The Cambridge Handbook of Psycholinguistics. Cambridge: Cambrigde University Press, 2012. p. 159-187.

COWLES, H. W. Psycholinguistics 101. New York: Springer Publishing Company, 2011.

DANEMAN, M. Individual differences in reading skills. In: BARR, R. et al. (Eds.). Handbook of reading research, v. 2, p. 512-538, 1996.

DEMO, P. Ser professor é cuidar que o aluno aprenda. 4. ed. Porto Alegre: Mediação, 2005.

KINTSCH, W.; RAWSON, K. A. Compreensão. In: SNOWLING, M. J.; HULME, C. (Org.). A ciência da leitura. Porto Alegre: Penso, 2013. p. 227244.

LEFFA, V. J. Aspectos da leitura: uma perspectiva psicolingüística. Porto Alegre: Sagra; DC Luzzatto, 1996.

LÚCIO, P. S.; PINHEIRO, A. M. V. Vinte anos de estudo sobre o reconhecimento de palavras em crianças falantes do português: uma revisão de literatura. Psicologia: Reflexão e Crítica, v. 24, n. 1, p. 170-179, 2009.

MORAIS, J.; KOLINSKY, R.; GRIMM-CABRAL, L. A aprendizagem da leitura segundo a psicolingüística cognitiva. In: RODRIGUES, C.; TOMITCH, L. M. B. (Org.). Linguagem e cérebro humano: contribuições multidisciplinares. Porto Alegre: Artmed, 2004. p. 53-69.

NATION, K.; SNOWLING, M. Assessing reading difficulties: the validity and utility of current measures of reading skill. British Journal of Educational Psychology, v. 67, n. 3, p. 359-370, set. 1997.

PERFETTI, C. A. On the value of simple ideas in reading instruction. In: BRADY, S. A.; SHANKWEILER D. P. (Eds.). Phonological processes in literacy. Hillsdale, NJ: Erlbaum, 1991. p. 211-218. 
SCLIAR-CABRAL, L. Guia prático de alfabetização, baseado em princípios do sistema alfabético do português do Brasil. São Paulo: Contexto, 2003a.

SCLIAR-CABRAL, L. Princípios do sistema alfabético do português do Brasil. São Paulo: Contexto, 2003b.

SEABRA, A. G.; CAPOVILLA, F. C. Teste de competência de leitura de palavras e pseudopalavras (TCLPP). São Paulo: Memnon, 2010.

SEIMETZ-RODRIGUES, C.; SOUZA, A. C. Ensino de leitura a surdos: o conhecimento do objeto de ensino e suas implicações para a prática pedagógica. Linguagem \& Ensino, v. 19, n. 1, p. 35-54, 2016.

SOUZA, A. C. Leitura, metáfora e memória de trabalho: três eixos imbricados. 2004. Tese. (Doutorado em Linguística) - Universidade Federal de Santa Catarina, Florianópolis.

SOUZA, A. C. Leitura emergente: a alfabetização como chave à produção de sentidos a partir do escrito. In: SOUZA, A. C.; GARCIA, W. A. C. A produção de sentidos e o leitor: os caminhos da memória. Florianópolis: NUP/CED, 2012. p. 43-60.

STANOVICH, K. E. Progress in understanding reading: Scientific foundations and new frontiers. New York: Guilford, 2000.

Recebido em: 28/01/2016 Aceito em: 29/04/2016 